\title{
CHARCOAL PRODUCTION FROM WOOD AND CELLULOSE: IMPLICATIONS TO RADIOCARBON DATES AND ACCELERATOR TARGET PRODUCTION
}

\author{
S W LEAVITT, D J DONAHUE*, and AUSTIN LONG \\ Department of Geosciences, University of Arizona \\ Tucson, Arizona 85721
}

\begin{abstract}
Radiocarbon dating with accelerators requires the manufacture of suitable carbon targets. Carbon yield and ${ }^{13} \mathrm{C}$ fractionation were investigated for the simple and direct pyrolysis of wood and cellulose to charcoal. Under continuous vacuum removal of evolved volatiles, carbon yields of 35 to $40 \%$ and $\delta^{13} \mathrm{C}$ fractionation of $-2.5 \%$ were observed in the pyrolysis of wood to charcoal, whereas yields of $30 \%$ and fractionation of $-0.8 \%$ were obtained in the pyrolysis of cellulose to charcoal. Yield and fractionation leveled off at temperatures above $300^{\circ} \mathrm{C}$. Yields and fractionations were also measured for pyrolysis of wood and cellulose in a continously-flowing argon atmosphere. Yields were higher and fractionations smaller than for the corresponding vacuum cases. For cellulose sealed in evacuated glass tubes and pyrolized at 550 to $600{ }^{\circ} \mathrm{C}$, carbon yields greater than $60 \%$ and fractionation of about $-0.5 \%$ were observed. Yields increased and fractionation tended to decrease as the ratio of tube volume/mass of cellulose decreased, $i e$, as the pressure increased. Reheating of this charcoal under continuous vacuum pumping revealed no loss of mass and no alteration of carbon isotopic composition. Fractionation measurements were additionally performed on wood and the charcoal produced from burning in a fireplace, conditions approximating the "natural" production of charcoal. Despite the large potential fractionation suggested in the wood pyrolysis experiments, charcoal produced in the fireplace showed very small or no fractionation.
\end{abstract}

\section{INTRODUCTION}

The advent of radiocarbon dating by tandem accelerator mass spectrometry (TAMS) (Bennet et al, 1977) has greatly enhanced prospects for determining ages of samples too small to date with conventional gasproportional or liquid-scintillation counting techniques. The anticipated procedure for accelerator dating will require extraction of carbon from the sample and production of a solid target which is most easily accommodated in a sputter-type ion source. Two important requirements of this method are: 1) maximizing the recovery and minimizing the isotopic fractionation during the conversion of the sample to the carbon target, and 2) obtaining satisfactory $\mathrm{C}^{-}$beam strength from the target. Methods of producing such targets can involve fairly elaborate chemical procedures, as in the cracking of acetylene to graphite on a hot filament (Hedges, Wand, and White, 1980). In this method, the cracking is only the final step and must be preceded by sample conversion to $\mathrm{CO}_{2}$, reaction of the $\mathrm{CO}_{2}$ with molten lithium to produce $\mathrm{Li}_{2} \mathrm{C}_{2}$, and finally, reaction of the cold $\mathrm{Li}_{2} \mathrm{C}_{2}$ with water to generate acetylene.

We have conducted a series of experiments to study the carbon yield and ${ }^{13} \mathrm{C}$ fractionation during the direct pyrolysis of wood and cellulose samples to charcoal in order to ascertain if such minimal treatment could yield carbon satisfactory for sputter ion source targets. Although recent tests of charcoal accelerator targets (Hedges, Wand, and White, 1980) revealed low $\mathrm{C}_{-}$- beam strengths relative to graphite, the target quality of charcoal carbon may possibly be upgraded by incorporation as a metal carbide or perhaps through the recently reported graphitiza-

* Department of Physics, University of Arizona 
tion of charcoal with chromium oxide catalysts (Mochida, Ohtsubo, and Takeshita, 1980). Results from the present experiments also revealed that additional errors may be introduced to radiocarbon dates of anthropologic charcoal samples, eg, from a campfire or hearth, if a $\delta^{13} \mathrm{C}$ correction for fractionation (Stuiver and Polach, 1977) is not applied.

\section{MATERIALS AND METHODS}

Wood was obtained from branches of a juniper tree (Juniperus monosperma) on the grounds of the University of Arizona. After bark removal, the sample was ground in a mill fine enough to pass through a 20 mesh screen. From one half of the ground wood, oils and resins were removed in a soxhlet extraction apparatus with toluene and ethanol solvents. One half of this resin-extracted wood was then treated with an acidified, heated sodium chlorite solution to isolate cellulose (holocellulose) in a procedure modified from that of Green (1963). Another similarly prepared cellulose sample was obtained from 700 -year-old wood of white fir (Abies concolor) from Casa Grande, Arizona.

In the first set of experiments, ca $28 \mathrm{mg}$ of sample, inserted in pyrex bulbs plugged with glass wool, was heated in a continuously-pumped vacuum furnace. (These will be referred to as our "regular" runs.) A thermocouple vacuum gauge allowed monitoring of degassing during heating. Additionally, two samples were pyrolyzed in a flowing argon atmosphere. Most samples were heated for 35 minutes to various temperatures from $200^{\circ}$ to $700^{\circ}$ (see table 1). Heating began from room temperature and normally attained the pre-set temperature within 5 minutes.

Charcoal was weighed after pyrolysis in order to determine the yield. To test for fractionation, the wood and charcoal samples were first burned to $\mathrm{CO}_{2}$ (measurements indicate complete conversion to $\mathrm{CO}_{2}$ ) in a micro-combustion system. The carbon isotopic composition was then measured as $\delta^{13} \mathrm{C}^{*}$ in $\%$ units relative to the PDB standard, on a Micromass $602 \mathrm{C}$ mass spectrometer. Analytical precision (combustion and measurement) is estimated to be $\pm 0.1 \%$.

The second set of experiments, also summarized in table 1 , was an effort to determine if pyrolysis of sealed samples would yield more carbon than that recovered in the regular vacuum runs. White fir cellulose samples were sealed in pyrex tubes under a vacuum and heated for 35 minutes at 550 to $600^{\circ} \mathrm{C}$.

Lastly, to explore the "natural" production of charcoal in fires, the charcoal and adjacent wood from logs (one orange tree, the other unidentified) burned in a household fireplace were collected and analyzed for ${ }^{13} \mathrm{C}$ fractionation. Also, a portion of wood from the 1979 growth ring of a juniper tree (Juniperus deppeana) from Prescott, Arizona, was placed into the fireplace fire until it was wholly charcoal (less than 5 minutes). A sample of original raw wood was retained for $\delta^{13} \mathrm{C}$ measurement to determine fractionation.

$$
* \delta^{13} \mathrm{C}=\left\{\frac{\left({ }^{1:} \mathrm{C} /{ }^{12} \mathrm{C}\right)}{\left({ }^{12} \mathrm{C} /{ }^{12} \mathrm{C}\right)} \begin{array}{l}
\text { sample } \\
\text { standard }
\end{array}-1\right\} \times 1000
$$


TABLE 1

Summary of pyrolysis results (masses and $\delta^{13} \mathrm{C}$ rounded to nearest tenth) Vacuum pyrolysis of juniper wood

\begin{tabular}{|c|c|c|c|c|c|}
\hline Sample & Temp/time & $\begin{array}{c}\text { Initial } \\
\text { wood } \\
\text { mass }\end{array}$ & $\begin{array}{l}\text { Final } \\
\text { chincoal } \\
\text { mass }\end{array}$ & $\begin{array}{l}\text { Carbon } \\
\text { yicld }\end{array}$ & $\delta^{13} \mathrm{C}$ \\
\hline CH-1 & $300^{\circ} \mathrm{C} / 35 \mathrm{~min}$ & $26.9 \mathrm{mg}$ & $4.0 \mathrm{mg}$ & $37 \%$ & $-25.0 \%$ \\
\hline СH-2 & $400 / 35$ & 27.7 & 4.3 & 39 & -25.2 \\
\hline $\mathrm{CH}-3$ & $200 / 35$ & 26.6 & 7.2 & 67 & -24.2 \\
\hline $\mathrm{CH}-4$ & $500 / 35$ & 27.5 & 9.7 & 33 & -25.2 \\
\hline CH -5 & $300 / 60$ & 26.9 & 4.7 & 44 & -24.9 \\
\hline CH-6 & $200 / 30 ; 500 / 35$ & 265 & 3.8 & 35 & -25.0 \\
\hline CH -7 & $\begin{array}{c}100 / 15 ; 200 / 15 \\
500 / 30\end{array}$ & 26.5 & 4.2 & 40 & -25.0 \\
\hline CHI-8 & $75 / 1$ week; $400 / 35$ & 26.3 & 4.0 & 38 & -25.1 \\
\hline $\mathrm{CH}-20 *$ & $500 / 35$ & 26.8 & 4.5 & 42 & -25.1 \\
\hline C.H-29: 冰 & $500 / 35 ; 650 / 45$ & 27.3 & 6.5 & 60 & -24.1 \\
\hline
\end{tabular}

* Resin-extracted wood

** Argon flow, no pumping

Vacuum pyrolysis of white fir cellulose

\begin{tabular}{lccccc}
\hline Sample & Temp/time & $\begin{array}{c}\text { Initial } \\
\text { cellulose } \\
\text { mass }\end{array}$ & $\begin{array}{c}\text { Final } \\
\text { charcoal } \\
\text { mass }\end{array}$ & $\begin{array}{c}\text { Carbon } \\
\text { yicld }\end{array}$ & $\delta^{\mathbf{1 3}} \mathbf{C}$ \\
\hline CH-9 & $300^{\circ} \mathrm{C} / 35 \mathrm{~min}$ & $29.2 \mathrm{mg}$ & $5.3 \mathrm{mg}$ & $41 \%$ & $-23.9 \%$ o \\
CH-10 & $400 / 35$ & 28.0 & 3.8 & 30 & -24.0 \\
CH-11 & $500 / 35$ & 27.8 & 3.6 & 30 & -23.9 \\
CH-12 & $600 / 35$ & 28.2 & 2.9 & 23 & -24.0 \\
CH-13 & $200 / 35$ & 28.4 & 12.1 & 97 & -23.4 \\
CH-14 & $250 / 35$ & 28.3 & 4.2 & 34 & -23.6 \\
CH-19* & $600 / 35$ & 28.6 & 4.5 & 36 & -23.8 \\
CH-18** & $600 / 35$ & 28.8 & 4.4 & 35 & -21.2 \\
CH-21** & $600 / 35$ & 28.5 & 3.9 & 31 & -21.6
\end{tabular}

* Argon flow, no pumping

** Cellulose from juniper wood

Pyrolysis of white fir cellulose in evacuated sealed tubes $(t=35 \mathrm{~m})$

\begin{tabular}{lllcccc}
\hline Sample & Temp & $\begin{array}{c}\text { Inside } \\
\text { volume }\end{array}$ & $\begin{array}{c}\text { Initial } \\
\text { cellulose } \\
\text { mass }\end{array}$ & $\begin{array}{c}\text { Final } \\
\text { charcoal } \\
\text { mass }\end{array}$ & $\begin{array}{c}\text { Carbon } \\
\text { yicld }\end{array}$ & $\delta^{13} \mathbf{C}$ \\
\hline CH-24 & $600^{\circ} \mathrm{C}$ & $3.7 \mathrm{~cm}^{3}$ & $10.6 \mathrm{mg}$ & $2.1 \mathrm{mg}$ & $46 \%$ & $-23.9 \%$ \\
CH-25 & 600 & 3.7 & 10.0 & 1.9 & 43 & -23.8 \\
CH-26 & 600 & 4.5 & 20.9 & 3.8 & 41 & -23.8 \\
CH-27 & 600 & 2.3 & 10.8 & 2.7 & 57 & -23.6 \\
CH-30 & 600 & 1.8 & 10.9 & 3.7 & 76 & -23.4 \\
CH-31 & 600 & 1.8 & 10.4 & 3.2 & 71 & -23.6 \\
CH-33 & 550 & 0.9 & 9.7 & 4.2 & 97 & -23.5 \\
CH-42 & 550 & 1.1 & 10.4 & 2.8 & 62 & -23.6 \\
CH-43 & 550 & 1.1 & 9.9 & 2.6 & 59 & Not \\
& & & & & & measured \\
\hline
\end{tabular}


RESULTS

Pyrolysis of whole wood in a vacuum

Figure 1 (see also table 1) depicts isotopic composition of charcoal produced from the juniper branches $\left(\delta^{13} \mathrm{C}_{\mathrm{wood}}=-22.6 \%\right.$ ). The carbon yield $(\%)$ calculations are based on the assumptions that charcoal formed during a pyrolysis run is all carbon, and that dry wood has the general composition $\mathrm{CH}_{2} \mathrm{O}$ so that ca $40 \%$ of the weight of the original wood is carbon. The product from the run at $200^{\circ} \mathrm{C}(\mathrm{CH}-3)$ was visibly brownish, suggesting that the first assumption does not hold at this temperature and, thus, the calculated yield at $200^{\circ} \mathrm{C}$ is certainly overestimated. Carbon yield appears to have greatest validity at temperatures above $300^{\circ} \mathrm{C}$ at which yields level off at 35 to $40 \%$ and carbonization has apparently gone to completion.

Pre-drying of the wood at $75^{\circ} \mathrm{C}$ (Sample CH-8) for one week and then pyrolyzing at $400^{\circ} \mathrm{C}$ yielded a point (figure 1) essentially identical to the regular run at $400^{\circ} \mathrm{C}$ (sample $\mathrm{CH}-2$ ). A run was conducted at $300^{\circ} \mathrm{C}$ (sample $\mathrm{CH}-5$ ) for 60 minutes to determine if pyrolysis had been carried out to its fullest extent in the 35 -minute runs. The $\delta^{13} \mathrm{C}$ result (figure 1) was nearly identical to the regular run at $300^{\circ} \mathrm{C}(\mathrm{CH}-1)$ and the yield was within $6 \%$. Two other tests (CH-6 and $\mathrm{CH}-7$, not illustrated) brought the temperature up in steps to $500^{\circ} \mathrm{C}$ during the runs. Neither of these runs (table 1) appears significantly different from the regular run at $500^{\circ} \mathrm{C}$ depicted in figure $1(\mathrm{CH}-4)$.

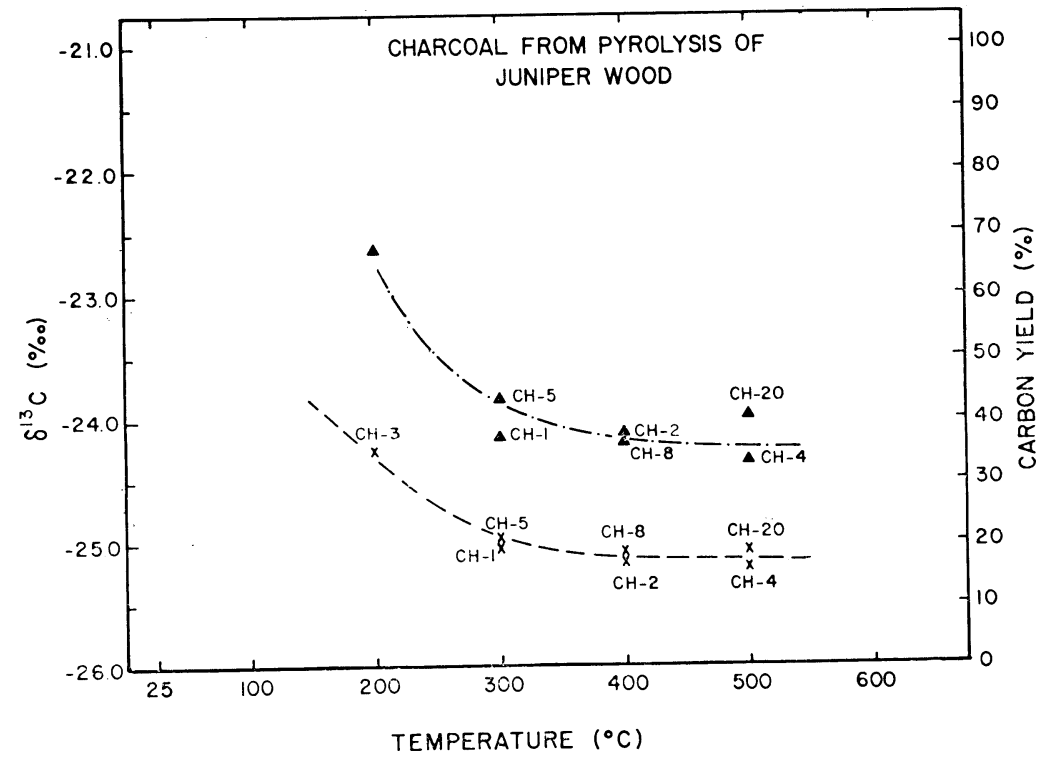

Fig 1. Carbon yield $(\mathbf{\Delta})$ and isotopic composition $(X)$ of charcoal produced by pyrolizing juniper wood under a continuously-pumping vacuum, as a function of temperature. $\delta^{13} \mathrm{C}$ of the whole wood is $-22.6 \% ; \delta^{13} \mathrm{C}$ of cellulose from this wood is ca $-20.7 \%$. 
Resin-extracted wood was pyrolized at $500^{\circ} \mathrm{C}(\mathrm{CH}-20)$. Toluene/ethanol extraction removed only ca $5 \%$ of the weight of the whole wood with the result that neither the $\delta^{13} \mathrm{C}$ of this wood nor its charcoal differed significantly from the normal runs with whole wood at $500^{\circ} \mathrm{C}(\mathrm{CH}-4)$. Some woods may have a higher proportion of extractives (eg, conifer heartwoods lose ca $10 \%$ upon extraction), components which tend to have more negative $\delta^{13} \mathrm{C}$ values (Park and Epstein, 1961). Consequently, the $\delta^{13} \mathrm{C}$ of such woods may be more affected by extraction.

A test was made to see if yields could be increased if argon was circulated over the sample during heating instead of the continuous vacuum pumping employed in the regular runs. Results from one run of whole wood in argon (CH-29, table 1) indicate increased yield and decreased fractionation relative to the regular run at $500^{\circ} \mathrm{C}$.

Pyrolysis of cellulose in a vacuum

For radiocarbon work with wood materials, it has been shown (Long et al, 1979) that the cellulose component (typically 40 to $50 \%$ of the weight of whole wood) has the greatest likelihood of retaining an isotopic composition representative of the year of growth. Therefore, we generated the pyrolytic charcoal curve in figure 2 from white fir cellulose $\left(\delta^{13} \mathrm{C}=-23.1 \%\right.$ ). Again, the $\delta^{13} \mathrm{C}$ curve for charcoal levels off above $300^{\circ} \mathrm{C}$, but the fractionation between the original cellulose and charcoal is only ca $-0.8 \%$. Carbon yields were determined with the assumption that $44 \%$ of the original cellulose (formula $\left.\left(\mathrm{C}_{6} \mathrm{H}_{10} \mathrm{O}_{5}\right)_{n}\right)$ was carbon. The

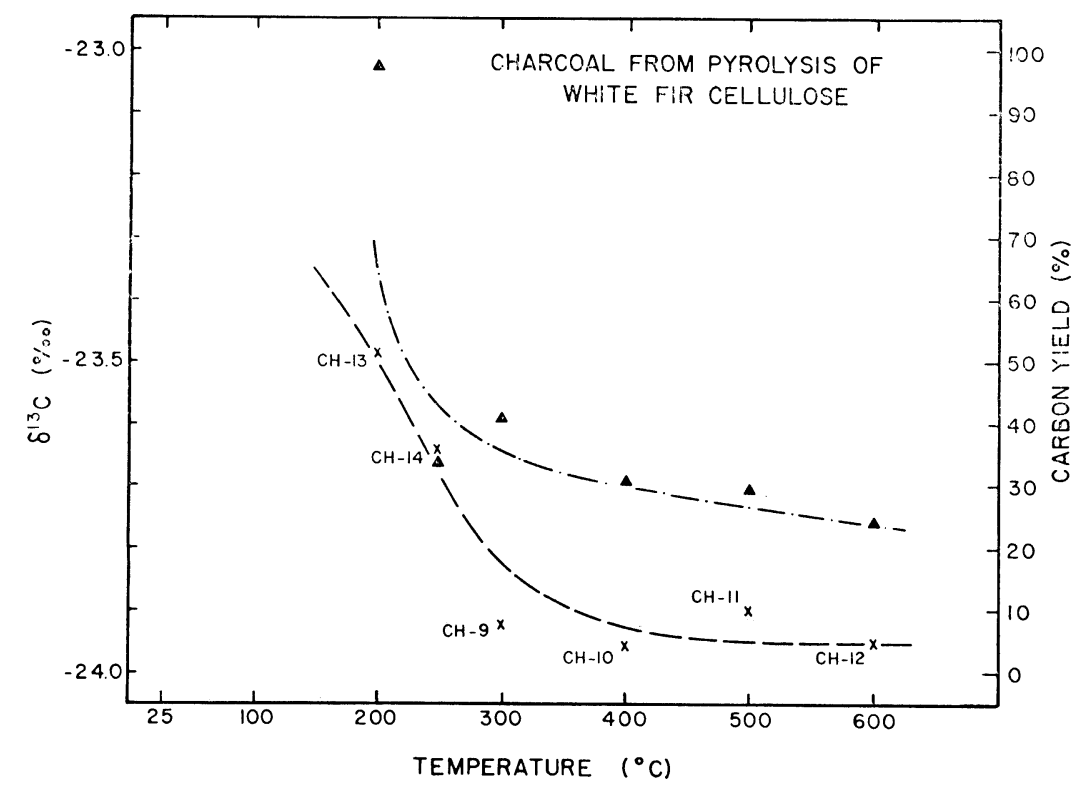

Fig 2. Carbon yield $(\boldsymbol{\Delta})$ and isotopic composition $(\times)$ of charcoal produced by pyrolizing white-fir cellulose under a continuously-pumping vacuum, as a function of temperature. $\delta^{13} \mathrm{C}$ of this white-fir cellulose is ca $-23.1 \%$. 
yield is similar to that observed for the whole wood runs, although the yield curve may not have fully leveled off by $600^{\circ} \mathrm{C}$. The "high" yield at $200^{\circ} \mathrm{C}$ (CH-13) is due to incomplete carbonization as indicated by the brownish color of the end product. A test in which argon was continuously run through the system during pyrolysis at $600^{\circ} \mathrm{C}(\mathrm{CH}-19)$ again yielded charcoal with a higher yield $(36 \%)$ and somewhat less fractionation $\left(\delta^{13} \mathrm{C}=-23.8 \%\right)$, although this decrease in fractionation relative to the regular run at $600^{\circ} \mathrm{C}$ may be within the errors of the measurements.

After this curve was generated and it became apparent that the full fractionation between cellulose and charcoal for this process could be determined at temperatures above $300^{\circ} \mathrm{C}$, cellulose from the juniper wood used to develop figure 1 was pyrolized to determined if fractionation was reproducible among species. Charcoal from two pyrolysis runs (CH-18,21) on this juniper wood cellulose at $600^{\circ} \mathrm{C}$ was isotopically lighter than the cellulose by an average of $0.6 \%$ as compared to a $0.8 \%$ difference between white fir cellulose and its charcoal (figure 2). Thus, the fractionation seen between this juniper wood cellulose and its charcoal is the same order of magnitude as for white fir cellulose and its pyrolysis charcoal.

\section{Pyrolysis of cellulose in sealed tubes}

In an effort to increase yield, cellulose was heated to 550 to $600^{\circ} \mathrm{C}$ for 35 minutes in evacuated, sealed pyrex tubes of various sizes. Details of these runs including $\delta^{13} \mathrm{C}$ of the product charcoals are summarized in table 1. Because smaller tube volumes were observed to puff out at $600^{\circ} \mathrm{C}$ (above annealing temperature of glass), tubes smaller than $1.8 \mathrm{~cm}^{3}$ were pyrolized at $550^{\circ} \mathrm{C}$. Further, both annealing after sealing the tubes and raising the temperature slowly to $550^{\circ} \mathrm{C}$ were helpful in preventing the glass from exploding during the initial stages of heating. For samples of approximately equal masses, a general trend of increasing carbon yield and decreasing fractionation was seen with decreasing volume. In order to include all the results into a single curve, regardless of initial cellulose mass, yield and $\delta^{13} \mathrm{C}$ were plotted versus the ratio of volume of the sealed tube to mass of the cellulose (figure 3). This volume/mass ratio for an ideal gas is inversely proportional to pressure so that on the abscissa in figure 3 , pressure would increase toward the left.

Carbon yields by this method (figure 3, table 1) are significantly increased relative to pyrolysis of cellulose under continuous vacuum pumping. The anomalously high yield of CH-33 is somewhat suspect because we were unable to reproduce it. For these higher yields the fractionation between cellulose and charcoal was ca -0.4 to $-0.5 \%$. This is less than the $-0.8 \%$ cellulose-to-charcoal fractionation seen in the regular pyrolysis runs at $600^{\circ} \mathrm{C}$ (figure 2).

A sample of charcoal produced by this method was placed in a glass bulb, reheated to $550^{\circ} \mathrm{C}$ for one hour under continous vacuum pumping, and showed no weight loss. Further, it had $\delta^{13} \mathrm{C}=-25.5 \%$, essentially identical to charcoal from other sealed-tube runs. 


\section{Fire experiments}

To examine fractionation during charcoal production under fire conditions, wood from a fireplace was examined. In the first test, partially burned wood of an unidentified species was removed from the fireplace. Isotopic analysis of charcoal and wood directly adjacent to it yielded identical $\delta^{13} \mathrm{C}$ values of $-23.2 \%$. Wood from an orange tree was then burned in the fireplace and the charcoal produced was found to have the same $\delta^{13} \mathrm{C}$ as the adjacent wood, $-23.4 \%$.

In a controlled experiment, one subsample of wood from the 1979 growth ring of a juniper tree was placed into a fireplace fire, while another subsample was not exposed to the fire. Several isotopic analyses were conducted and revealed the charcoal to be lighter than the wood by $0.3 \%$ o (-22.8 vs $-23.1 \%$ ). This fractionation is much less than that seen in the regular pyrolysis experiments with whole wood and similar to that observed in pyrolysis of cellulose.

\section{DISCUSSION AND CONCLUSIONS}

Based on the results of our experiments, several conclusions can be drawn which are discussed below.

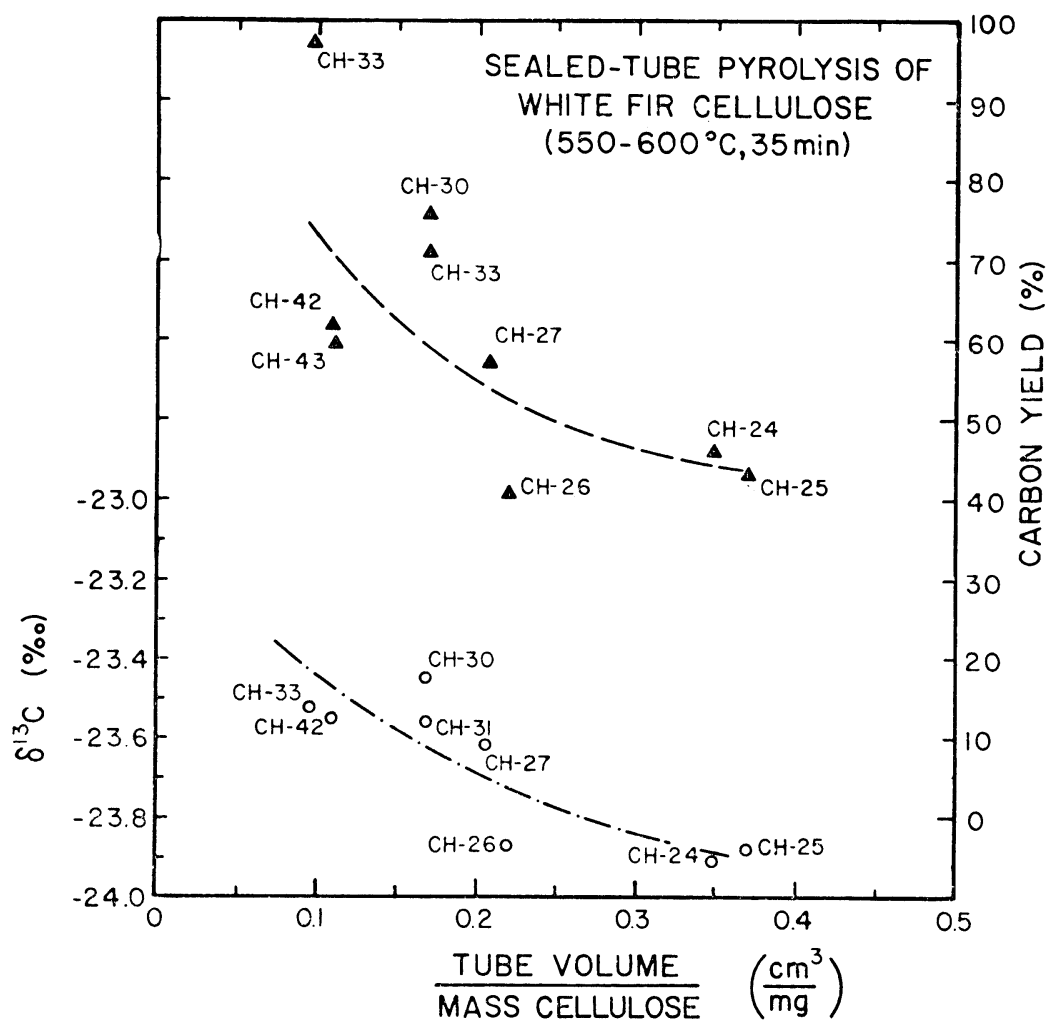

Fig 3. Carbon yield $(\mathbf{\Delta})$ and isotopic composition $(O)$ of charcoal produced by pyrolizing white-fir cellulose in sealed, evacuated tubes, as a function of tube volume/ cellulose mass. Pressure would increase to the left on the abscissa. 
1) In the direct pyrolysis of wood to charcoal in a vacuum, yields Mass of Product Charcoal $)$ of between 25 and $40 \%$ were Mass of Carbon in Original Wood
obtained at temperatures above $300^{\circ} \mathrm{C}$ in runs of 35 minutes. In this process, ${ }^{13} \mathrm{C}$ fractionation as determined from the difference between the $\delta^{13} \mathrm{C}$ of the wood and the charcoal amounted to ca $-2.5 \%$.

2) ${ }^{13}$ C fractionation during the "natural" production of charcoal was determined from several woods burned in a fireplace. Fractionation was quite small and near or within the uncertainties of the measurements (ca $0.1 \%$ ).

The primary difference between our pyrolysis of wood and the "natural" production is the pumping away of vapors as they are evolved during pyrolysis. In the fireplace fire, the wood is bathed in flame and a gaseous atmosphere $\left(\mathrm{CO}_{2}, \mathrm{CO}, \mathrm{H}_{2} \mathrm{O}, \mathrm{O}_{2}\right.$ and hydrocarbons). Other differences may include temperature, surface area (ground samples in pyrolysis, large pieces in fireplace), and the possibility of heat and/or smoke alteration of wood adjacent to the charcoal which was taken as the "raw" wood.

3) Pyrolysis of cellulose to charcoal in a vacuum or in a circulating argon atmosphere resulted in yields $\left(\frac{\text { Mass of Product Charcoal }}{\text { Mass of Carbon in Original Cellulose }}\right)$ of 25 to $40 \%$ in the 35 -minute runs at temperatures above $300^{\circ} \mathrm{C} .{ }^{13} \mathrm{C}$ fractionation of -0.6 to $-0.8 \%$ was observed.

4) Experiments on the pyrolysis of cellulose to charcoal in sealed, evacuated tubes indicate that the carbon yields can be increased as the ratio of $\frac{\text { Inside Tube Volume }}{\text { Initial Mass of Cellulose }}$ is decreased, $i e$, as the pressure is increased. Yields of $60 \%$ and higher were obtained at temperatures of 550 to $600^{\circ} \mathrm{C}$. Fractionation in these tubes, typically ca $-0.5 \%$, shows evidence of decreasing with increasing pressure. Later heating of this charcoal under vacuum pumping produced no weight loss and no alteration of its isotopic composition.

5) In all of the experiments, the observed fractionation was negative, $i e$, the charcoal was lighter than the original material. For the wood pyrolysis, this fractionation was especially pronounced. This negative fractionation for ${ }^{13} \mathrm{C}$ occurs despite several processes which should make the charcoal product "heavier" (enriched in ${ }^{13} \mathrm{C}$ ). These include, a) the expected early weight losses during heating which should include large contributions from components of relatively high volatility such as oils and resins, compounds which tend to be depleted in ${ }^{13} \mathrm{C}$ relative to compounds such as cellulose (Park and Epstein, 1961); b) for specific organic compounds, molecules enriched in ${ }^{12} \mathrm{C}$ would have higher vapor pressures and, hence, enrichment of the residual material in ${ }^{13} \mathrm{C}$; c) the higher zero-point energies of ${ }^{12} \mathrm{C}$ bonds would result in greater ease of breaking during pyrolysis and enhance ${ }^{12} \mathrm{C}$ loss.

The fractionation observed is, however, in the direction expected for isotopic equilibrium between graphite and carbon dioxide (Bottinga, 
1969), if $\mathrm{CO}_{2}$ was one of the predominant gases in the sealed pyrolysis tubes. A quantitative prediction of equilibrium isotopic compositions in the experimental tubes is not possible due to, a) the lack of fractionation factor data for all gases probably involved, and b) the probability of significant amounts of thermodynamically unstable gases.

6) The ${ }^{13} \mathrm{C}$ fractionation of $-2.5 \%$ in wood pyrolysis in a vacuum would imply a ${ }^{14} \mathrm{C}$ fractionation (Craig, 1954) of ca $-0.5 \%$, equivalent to an additional error of ca 40 years on a charcoal date not corrected by stable carbon isotope analysis. The smaller ${ }^{13} \mathrm{C}$ fractionation observed for cellulose pyrolysis implies an age error of ca 10 years for uncorrected dates. Despite the minimal fractionation seen in the production of "natural" charcoal (fireplace), perhaps representative of the processes which produce most charcoal of use to anthropologists, our vacuum pyrolysis of wood reveals a potential for substantial fractionation in "natural" samples and underscores the importance of normalization of ${ }^{14} \mathrm{C}$ activities and ages to $\delta^{13} \mathrm{C}=-25 \%$ as recommended by Stuiver and Polach (1977).

7) Overall, charcoal is attractive for carbon accelerator targets because of its relative ease of preparation from wood or cellulose compared to some of the other methods of carbon production. Additionally, fractionation is small relative to the expected precision of accelerator measurements and is reproducible. The yields are high relative to some of the other methods.

\section{ACKNOWLEDGMENT}

This work was supported by a National Science Foundation Regional Instrumentation Facilities grant, CHE 78-18576.

REFIRENCES

Bennett, C L, Beukens, R P, Clover, M R, Gove, H E, Liebert, R B, Litherland, A E, Purser, K H, and Sondheim, W E, 1977, Radiocarbon dating using electrostatic accelerators: negative ions provide the key: Science, v 198, p 508-510.

Bottinga, Y, 1969, Carbon isotope fractionation between graphite, diamond and carbon dioxide: Earth Planetary Sci Letters, v 5, p 301-307.

Craig, Harmon, 1954, Carbon-13 in plants and the relationship between carbon-13 and carbon-14 variations in nature: Jour Geol, v 62, p 115-149.

Green, J W, 1963, Wood cellulose, in Whistler, R L, ed, Methods of carbohydrate chemistry: New York, Academic Press, p 9-21.

Hedges, R E M, Wand, J O, and White, N R, 1980, The production of C- beams for radiocarbon dating with accelerators: Nuclear Instruments and Methods, $v$ 173, p 409-421.

Long, Austin, Arnold, L D, Damon, P E, Ferguson, C W, Lerman, J C, and Wilson, A T, 1979, Radial translocation of carbon in bristlecone pine, in Berger, Rainer and Suess, H, eds, Radiocarbon dating, Internatl radiocarbon conf, 9th, Proc: Berkeley/Los Angeles, Univ California Press, p 532-537.

Mochida, I, Ohtsubo, R, and Takeshita, K, 1980, Catalytic graphitization of nongraphitizable carbon by chromium and manganese oxides: Carbon, v 18, p 117-123.

Park, R and Epstein, S, 1961, Metabolic fractionation of ${ }^{13} \mathrm{C} /{ }^{12} \mathrm{C}$ in plants: Plant Physiology, v 36, p 133-138.

Stuiver, Minze and Polach, H A, 1977, Reporting of ${ }^{14} \mathrm{C}$ data: Radiocarbon, v 19, p $355-363$. 